Research Article

\title{
Studi Eksperimental Pergerakan Temperatur Radiator Terhadap Putaran Mesin (Rpm) Dengan Kecepatan Kipas Constant
}

\author{
Andi Prasetyo ${ }^{1}$ dan Arif Surono ${ }^{2}$ \\ ${ }^{1}$ Teknik Mesin, Fakultas Teknik, Universitas Nahdlatul Ulama Surakarta, Indonesia \\ ${ }^{2}$ Teknik Mesin, Politeknik Indonusa Surakarta, Indonesia \\ Email:Andiprast80@gmail.com, Arifsurono@poltekindonusa.ac.id
}

Corespondensi author : Andiprast80@gmail.com

\section{Article History:}

Online first:

18 January 2021

Keywords: Temperature, Radiator, Engine rotation.

Kata Kunci: Temperatur, Radiator, Putaran mesin

\section{ABSTRACT}

The research aims to evaluate the engine rotation (rpm) against changes in radiator temperature. Radiator used is compact heat exchanger tube and fins type. The study was conducted using an experimental method on a BMW E.36 car with a stop state. The research scheme we use consists of radiator water reservoir tanks, water pumps, and radiators. Measuring instruments used are anemometer, thermocople, stopwatch and reader. Data retrieval is carried out at the radiator entrance temperature, radiator exit temperature and the temperature on the radiator wall that hits the fan. In this study we did variations of engine rotation (rpm) of 1000, 1500, 2000, 2500 and $3000 \mathrm{rpm}$. The results showed that in the use of fans at a speed of $6.5 \mathrm{~m} / \mathrm{s}$ able to throw heat into the environment well, it is proven that the highest temperature at minute 30 is $84^{\circ} \mathrm{C}$ at a fan speed of $6.5 \mathrm{~m} / \mathrm{s}$ at $3000 \mathrm{rpm}$. While at $2500 \mathrm{rpm}$ the maximum temperature reaches $80.3{ }^{\circ} \mathrm{C}$. While at the engine speed of $1000 \mathrm{rpm}$ the maximum temperature reaches 48.6 ${ }^{o} \mathrm{C}$.

\section{ABSTRAK}

Penelitian ini bertujuan untuk mengevaluasi putaran mesin (rpm) terhadap perubahan temperatur pada radiator. Radiator yang digunakan adalah type compact heat exchanger tube and fins. Penelitian ini dilakukan dengan metode eksperimental pada sebuah mobil BMW E.36 dengan keadaan berhenti. Skema penelitian yang kami gunakan terdiri dari tangki reservoir penampung air radiator, water pump, dan radiator. Alat ukur yang digunakan adalah anemometer, termokople, stopwatch dan reader. Pengambilan data dilakukan pada temperatur masuk radiator, temperatur keluar radiator dan temperatur pada dinding radiator yang mengenai kipas. Pada penelitian ini kami melakukan variasi putaran mesin (rpm) sebesar 1000, 1500, 2000, 2500 dan 3000 rpm. Hasil penelitian menunjukkan bahwa pada penggunaan kipas pada kecepatan 6,5 $\mathrm{m} / \mathrm{s}$ mampu membuang panas ke lingkungan dengan baik, hal ini 
terbukti bahwa temperatur tertinggi pada menit ke 30 sebesar $84{ }^{\circ} \mathrm{C}$ pada kecepatan angin pada kipas sebesar $6,5 \mathrm{~m} / \mathrm{s}$ pada $3000 \mathrm{rpm}$. Sedangkan pada $2500 \mathrm{rpm}$ temperatur maksimal mencapai $80,3{ }^{\circ} \mathrm{C}$. Sedangkan pada kecepatan mesin 1000 rpm temperature maksimal mencapai $48,6^{\circ} \mathrm{C}$.

\section{PENDAHULUAN}

Melihat tantangan saat ini optimasi kinerja dari sebuah kendaraan mengalami peningkatan yang signifikan. Dengan adanya proses optimasi diharapkan mampu meningkatkan kinerja dari mesin [1]. Salah satu komponen penting dalam kendaraan adalah sistem pendinginan radiator. Sistem ini digunakan sebagai media pendingin mesin dengan menyerap kalor yang dihasilkan akibat proses pembakaran yang terjadi didalam silinder mesin. Panas tersebut apabila dibiarkan maka akan menimbulkan panas yang berlebih (over heating). Panas yang berlebihan akan mengakibatkan berubahnya sifat-sifat mekanis dan bentuk dari komponen mesin [2]

Pada umumnya media yang digunakan sebagai pendingin berupa fluida air untuk melakukan proses perpindahan panas. Pada sistem ini cairan didinginkan melalui sirkulasi pendingin yang terdiri dari upper tank, reservoir tank, fan, wall, fins, pipe, lower tank, dan pipa yang disambungkan kedalam engine. Cairan pendingin disirkulasi dalam sistem dengan bantuan pompa, karena pengaruh pendingin yang terjadi pada sistem alat penukar kalor maka panas yang ada pada sistem tersebut berangsur-angsur hilang akibat perangkat pendingin dalam sistem tersebut.

Proses perpindahan panas dengan debit fluida yang tinggi berdampak pada radiator dari dinding ke fluida yang bersirkulasi semakin banyak kalor yang diserap oleh [2]. Debit yang semakin tinggi ini dikarenakan putaran mesin yang semakin tinggi sehingga menjadikan penyerapan kalor menjadi lebih optimal [3]. Selain itu, semakin berkurangnya volume air radiator maka temperatur mesin mengalami kanikan temperatur yang signifikan, dan efisiensi radiator menurun seiring dengan berkurangnya volume radiator [4].

Berdasarkan uraian diatas maka peneliti tertarik untuk melakukan penelitian terkait perubahan temperatur yang terjadi pada mesin dengan melakukan variasi putaran mesin dan kecepatan kipas pada radiator yang digunakan. Tingkat keberhasilan yang dicapai radiator dengan melakukan variasi putaran mesin, dengan penambahan pengambilan data parameter sebagi acuan untuk meneliti lebih lanjut sehingga diharapkan kinerja mesin lebih optimal.

\section{PRINSIP KERJA RADIATOR}

Kondisi mesin pada ruang bakar mengalami peningkatan temperatur karena terjadinya proses pembakaran udara dan bahan bakar yang terjadi didalam ruang bakar. Panas tersebut dipindahkan dari sisi dalam silinder ke water jacket secara konduksi [5]. Selanjutnya, panas yang bersirkulasi didalam water jacket diteruskan ke fluida pendingin (air dan coolant) secara konveksi. Sehingga mengakibatkan air yang keluar menjadi panas. Air yang telah menjadi panas ini dipompakan ke radiator untuk didinginkan lagi agar mampu meyerap panas.

Air panas yang keluar dari dalam engine masuk ke upper tank melalui upper hose, selanjutnya ke lower tank melalui tube pada radiator core dan keluar dari tank melalui lower hose dalam bentuk air dingin. Air yang sudah didinginkan pada engine tersebut disirkulasikan melalui water jacket untuk melakukan penyerapan kalor pada engine [7].

Proses pelepasan kalor pada radiator terjadi pada radiator core. Air panas yang mengalir pada tube memindahkan panas dari air (fluida pendingin) ke permukaan tube secara 
konveksi. Kemudian panas dipindahkan dari permukaan dalam ke permukaan luar tube secara konduksi, dan diteruskan lagi ke permukaan luar tube ke fins (sirip-sirip radiator) secara konduksi. Panas pada fin radiator dilepaskan ke udara luar dengan proses konveksi [6].

\section{METODE PENELITIAN}

\section{Alat dan bahan}

Alat-alat yang digunakan pada penelitian ini diantaranya: satu unit mobil, termocouple, stopwatch, dan alat bantu seperti obeng, tang ember. Bahan yang digunakan diantaranya : air murni, auto sealant, dan klem.

\section{Metode Pelaksanaan}

Pengujian dilaksanakan menggunakan fluida $100 \%$ air murni dan coolant dengan variasi putaran mesin 1000, 1500, 2000, 2500 dan 3000 rpm. Pengujian dimulai dengan fluida 100\% air dan coolant murni pada 1000, 1500, 2000, 2500 dan $3000 \mathrm{rpm}$. Catat temperatur fluida pada inlet radiator $\left(\mathrm{T}_{\mathrm{in}}\right)$ dan outlet radiator $\left(\mathrm{T}_{\text {out }}\right)$ pada kondisi awal, kemudian mesin dihidupkan. Pengujian dilakukan selama 30 menit pada setiap variasi rpm dan data yang dicatat setiap satu menit.

Langkah-langkah pengambilan data sebagai berikut :

1. Siapkan alat dan bahan serta alat uji yang akan digunakan

2. Masukkan fluida pendingin kedalam radiator sesuai dengan kapasitas radiator yang disarankan.

3. Catat temperatur fluida pendingin dan temperatur pada dinding radiator pada sisi masuk dan keluar radiator.

4. Hidupkan mesin, mula-mula pada rpm 1000 kemudian ditambah sampai $3000 \mathrm{rpm}$.

5. Cata data pada setiap 1 menit terhitung saat mesin dihidupkan. pengujian dilakukan selama 30 menit.

6. Ulangi pengambilan data pengujian sebanyak 5 kali sesuai dengan banyaknya variasi yang dilakukan.

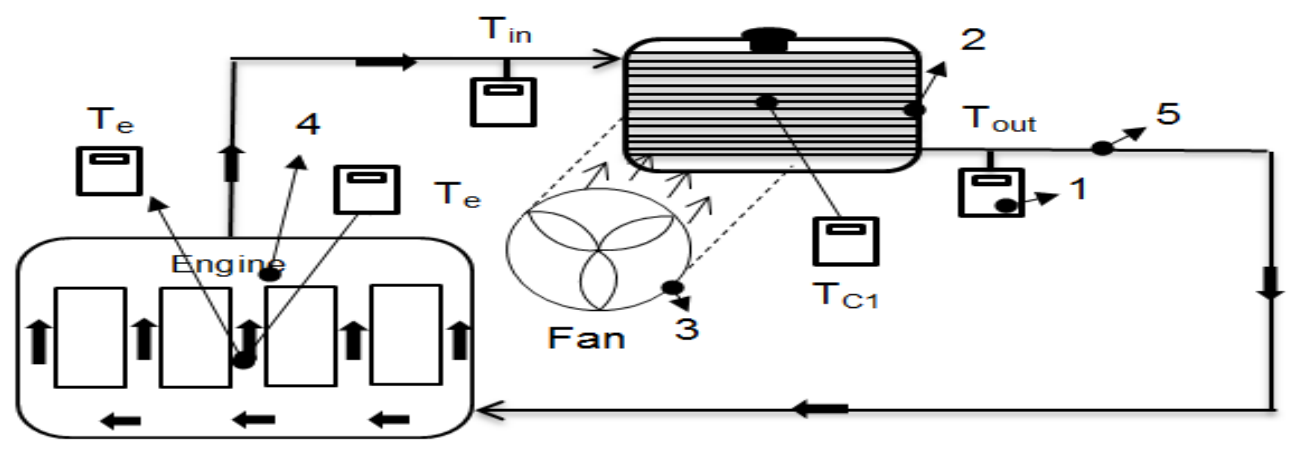

Gambar 1. Skema Penelitian

1. Termokople reader 2. Radiator 3. Kipas (Fan) 4. Mesin (Engine)

5. Pipa Radiator 


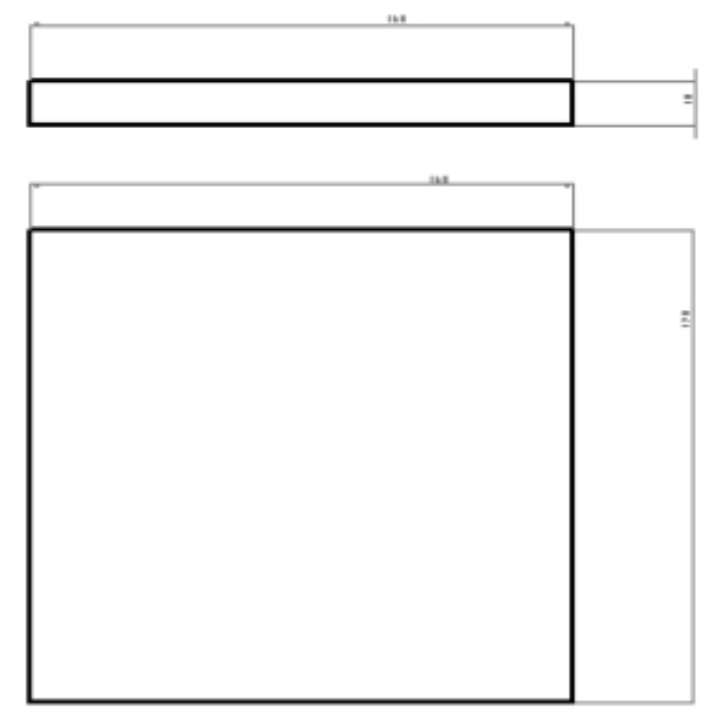

Gambar 2. Pandangan Depan dan Atas Permukaan Radiator

Tabel 1. Spesifikasi Radiator

\begin{tabular}{lll}
\hline No & \multicolumn{1}{c}{ Data } & \multicolumn{1}{c}{ Nilai } \\
\hline 1. & Tipe Radiator & $\begin{array}{l}\text { Compact heat exchanger flat tube, } \\
\text { flat fin }\end{array}$ \\
2. & Volume Radiator & $\begin{array}{l}\text { P x } \mathrm{L} \mathrm{T}=450 \mathrm{~mm} \times 40 \mathrm{~mm} \times \\
420 \mathrm{~cm}\end{array}$ \\
& & Tebal $2 \mathrm{~mm} \times$ lebar $40 \mathrm{~mm} \times$ \\
3. & Luas tube & panjang $45 \mathrm{~mm}$ \\
& & $450 \mathrm{~mm}$ \\
4. & Panjang tube & 43 \\
5. & Jumlah baris tube & 2 \\
6. & Jumlah tube tiap baris & $10 \mathrm{~mm}$ \\
7. & Jarak antar tube & Aluminium \\
8. & Bahan & \\
\hline
\end{tabular}

\section{HASIL DAN DISKUSI}

Data pengujian yang telah dilakukan didapatkan dari data eksperimen. Mesin yang digunakan dalam penelitian ini adalah mesin BMW E.36. Pengambilan data penelitian ini dilakukan dengan mengukur suhu yang bersirkulasi pada instrumen peralatan radiator. Pengambilan data secera keseluruhan dari variasi kecepatan udara pada kipas $(3,5 ; 4,5 ; 6,5) \mathrm{m} / \mathrm{s}$ dengan putaran mesin konstan 1000, 1500, 2000, 2500 dan 3000 rpm.

Dari hasil pengambilan data dan perhitungan tersebut, kemudian dianalisis grafik dari temperatur in, out dan engine pada radiator terhadap waktu seperti yang dijelaskan pada gambar dibawah. 


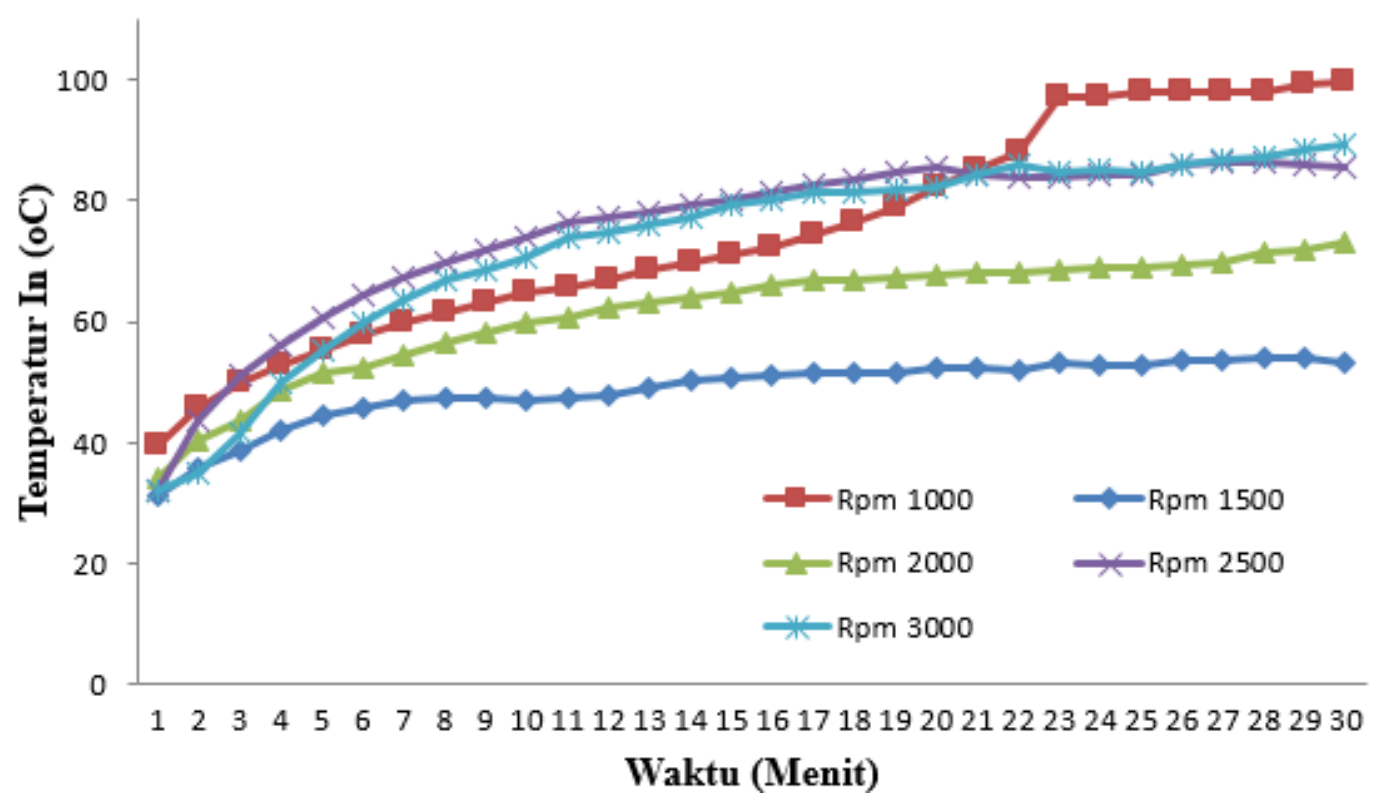

Gambar 3. Temperatur masuk (in) radiator $\left({ }^{\circ} \mathrm{C}\right)$ terhadap waktu (Menit)

Pada pengujian menunjukkan bahwa temperatur masuk (in) pada sisi radiator pada masing-masing kecepatan mengalami penurunan. Ini disebakan karena seiring dengan penambahan laju kecepatan angin maka kemampuan udara untuk mendinginkan radiator lebih cepat. Temperatur mulai stabil grafiknya dimulai pada menit ke-15 yang mana masing-masing kecepatan mengalami kenaikan temperatur yang seimbang. Temperatur tertinggi pada menit ke 30 sebesar $84{ }^{\circ} \mathrm{C}$ pada kecepatan angin pada kipas sebesar $6,5 \mathrm{~m} / \mathrm{s}$ pada $3000 \mathrm{rpm}$. Sedangkan pada $2500 \mathrm{rpm}$ temperatur maksimal mencapai $80,3{ }^{\circ} \mathrm{C}$. Sedangkan pada kecepatan mesin $1000 \mathrm{rpm}$ temperature maksimal mencapai $48,6{ }^{\circ} \mathrm{C}$. Temperaturnya menurun seiring dengan proses laju pembuangan panas pada radiator yang baik dimana panas pada radiator dibuang ke lingkungan.

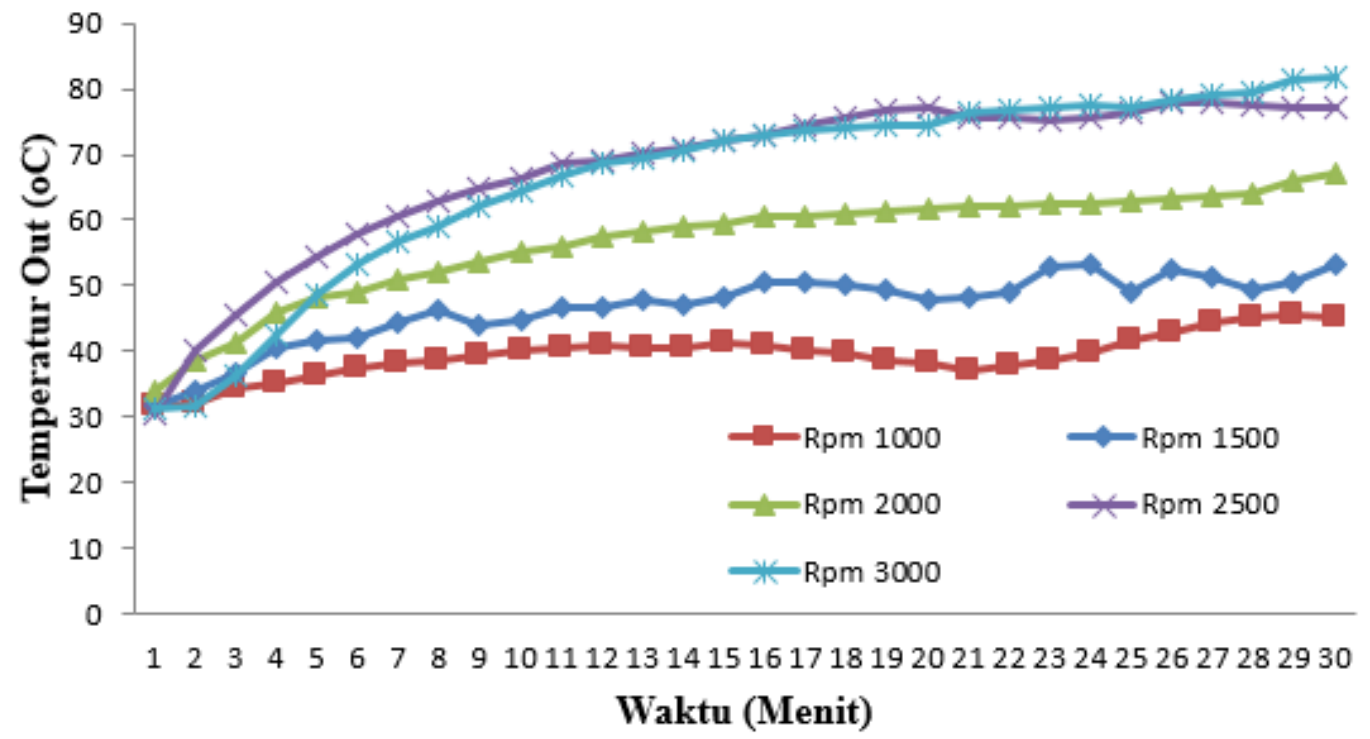

Gambar 4. Grafik Temperatur out radiator $\left({ }^{\circ} \mathrm{C}\right)$ terhadap waktu (Menit) 
Hasil analisa menunjukkan bahwa temperatur keluar (out) pada sisi radiator pada masing-masing kecepatan mengalami kenaikan. Ini disebakan karena seiring dengan penambahan laju kecepatan angin maka kemampuan udara untuk mendinginkan radiator mengalami penurunan. Temperatur mulai stabil grafiknya dimulai pada menit ke 18 dimana rata-rata temperatur sebesar $61^{\circ} \mathrm{C}$ pada kecepatan angin $6,5 \mathrm{~m} / \mathrm{s}$ pada $2000 \mathrm{rpm}$. Temperatur tertinggi pada menit ke 30 sebesar $89,4{ }^{\circ} \mathrm{C}$ pada kecepatan angin pada kipas sebesar $6,5 \mathrm{~m} / \mathrm{s}$ dan dalam kondisi $3000 \mathrm{rpm}$. Sedangkan pada menit ke 10 temperatur terendah didapatkan dari kecepatan $6,5 \mathrm{~m} / \mathrm{s}$ sebesar $53,2^{\circ} \mathrm{C}$ pada kecepatan mesin $1500 \mathrm{rpm}$.

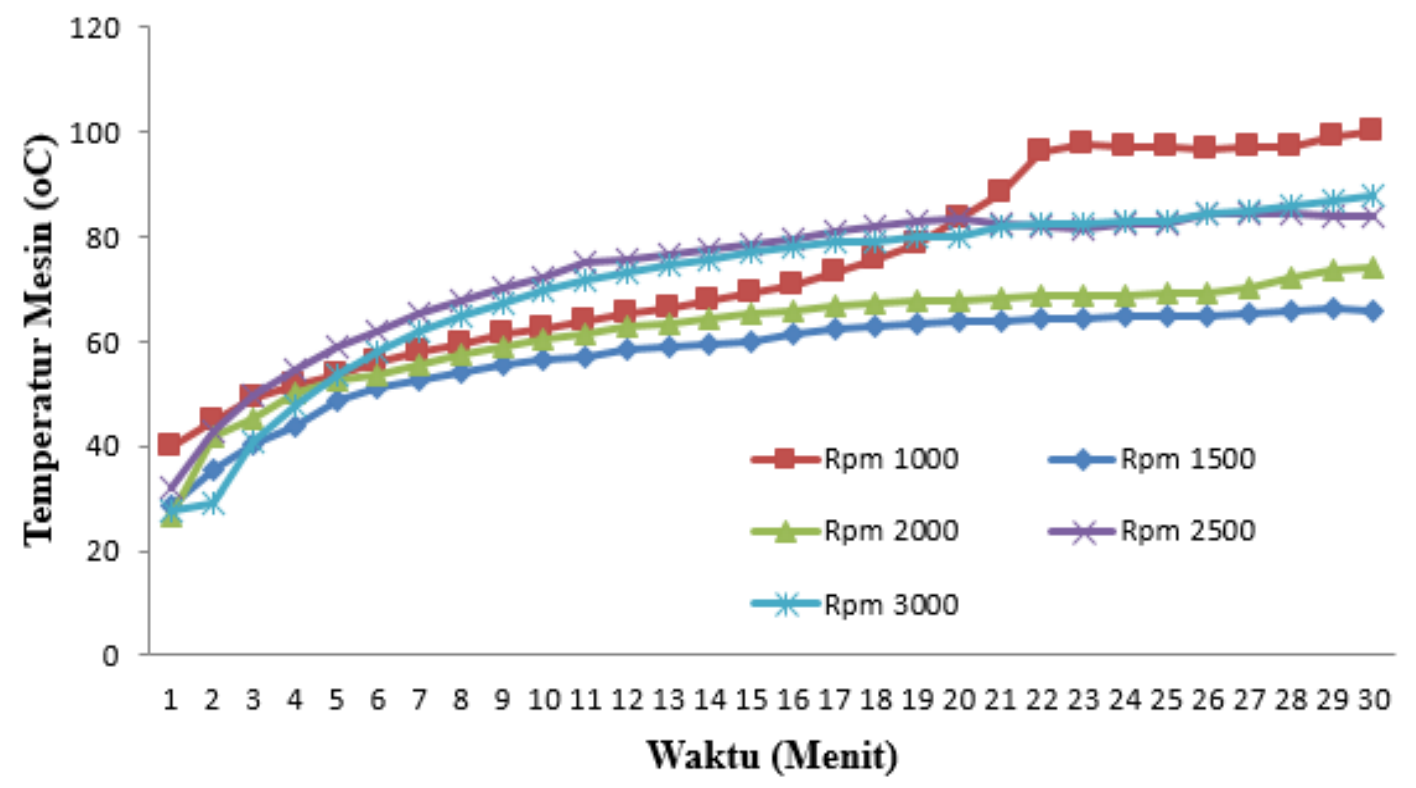

Gambar 5. Temperatur mesin $\left({ }^{\circ} \mathrm{C}\right)$ terhadap waktu (Menit)

Dari gambar diatas menunjukkan bahwa temperatur mesin pada masing-masing variasi kecepatan mesin (rpm) mengalami kenaikan seiring dengan bertambahnya waktu. Hal ini disebakan karena seiring dengan penambahan kecepatan mesin maka kemampuan udara untuk mendinginkan radiator lebih lama karena suplai panas dari mesin lebih cepat. Temperatur mulai stabil grafiknya dimulai pada putaran mesin 3000 terjadi pada menit ke tujuh yang mana sebesar $61^{\circ} \mathrm{C}$ kemudian mengalami kenaikan temperatur yang merata. Sedangkan pada putaran mesin $2000 \mathrm{rpm}$ temperatur mesin stabil pada menit ke 10 sebesar $60,3{ }^{\circ} \mathrm{C}$. Temperatur maksimal pada kecepatan mesin $3000 \mathrm{rpm}$ pada menit ke 30 yaitu sebesar $87,7^{\circ} \mathrm{C}$. Temperatur mesin mengalami peningkatan seiring dengan proses laju pembuangan panas pada mesin yang dibuang kelingkungan akibat pembakaran.

\section{KESIMPULAN}

Berdasarkan hasil pengamatan, analisis data dan pembahasan diketahui bahwa pada penggunaan kipas pada kecepatan $6,5 \mathrm{~m} / \mathrm{s}$ mampu membuang panas ke lingkungan dengan baik, hal ini terbukti bahwa temperatur tertinggi pada menit ke 30 sebesar $84{ }^{\circ} \mathrm{C}$ pada kecepatan angin pada kipas sebesar $6,5 \mathrm{~m} / \mathrm{s}$ pada $3000 \mathrm{rpm}$. Sedangkan pada $2500 \mathrm{rpm}$ temperatur maksimal mencapai $80,3{ }^{\circ} \mathrm{C}$. Sedangkan pada kecepatan mesin $1000 \mathrm{rpm}$ temperature maksimal mencapai $48,6^{\circ} \mathrm{C}$. 


\section{DAFTAR PUSTAKA}

[1] Simamora, F.D., Sappu. P. F., Ulaan Y. V.T., 2015. Analisis Efektivitas Radiator Pada Mesin Toyota Kijang TIPE 5 K., Jurnal Online Poros Teknik Mesin Vol. 4 No. 2.

[2] Nazzaruddin., Yuliani., 2013., Analisa Debit Aliran Fluida Terhadap Efektivitas Radiator., JURNAL APTEK Vol. 5 No. 1 Januari 2013.

[3] Prasetyo, T. B. 2007. Pengujian Karakteristik Unjuk Kerja Radiator., MESIN, Vol. 9 No. 2, Mei 2007, 107-113.

[4] Soebiyakto, G. 2012., Analisis Volume Air Radiator Terhadap Perubahan Temperatur Pada Motor Diesel Chevrolet., PROTON, Vol. 4 No 1/Hal. 1-5.

[5] Wiryanta, H. E. K. I. 2017., Studi Eksperimental Unjuk Kerja Radiator Pada Sumber Energi Panas Pada Rancang Bangun Simulasi Alat Pengering., JURNAL LOGIC, VOL. 17. NO. 2, JULI 2017.

[6] Parashurama, M. S., Dhananjaya, D. A., Kumar N, R. R. 2015., Experimental Study of Heat Transfer in a Radiator using Nanofluid., IJEDR., Vol 3. Issue 2., ISSN: 2321-9939.

[7] Prasetyo, Y. 2006., Pengaruh Debit Aliran Terhadap Efektivitas Radiator., Skripsi, S1 Pendidikan Teknik Mesin, UNNES.

[8] Hollman, J.P. 1999., Perpindahan Kalor., Erlangga : Jakarta. 